Article

\title{
4862F, a New Inhibitor of HIV-1 Protease, from the Culture of Streptomyces I03A-04862
}

Xiao Liu ${ }^{1,2}$, Maoluo Gan ${ }^{1}$, Biao Dong ${ }^{1}$, Tian Zhang ${ }^{1}$, Yongzhen Li ${ }^{1}$, Yuqin Zhang ${ }^{1}$, Xiuyong Fan ${ }^{1}$, Yexiang Wu ${ }^{1}$, Shuoke Bai ${ }^{1}$, Minghua Chen ${ }^{1}$, Liyan Yu ${ }^{1}$, Peizhen Tao ${ }^{1}$, Wei Jiang ${ }^{1}$ and Shuyi Si ${ }^{1, *}$

1 Institute of Medicinal Biotechnology, Peking Union Medical College, Chinese Academy of Medical Sciences, Tiantanxili No.1, Beijing 100050, China; E-Mail: liuxiao503@gmail.com (X.L.)

2 National Institute of Biological Sciences, 7 Science Park Road, Zhongguancun Life Science Park, Beijing 102206, China

* Author to whom correspondence should be addressed; E-Mail: sisyimb@hotmail.com; Tel./Fax: +86-10-6318-0604.

Received: 31 October 2012; in revised form: 14 December 2012 / Accepted: 18 December 2012 / Published: 27 December 2012

\begin{abstract}
We have isolated an extraordinary pentapeptide, called 4862F, from the culture broth of Streptomyces albosporus I03A-04862 by Diaion HP-20 macroporous adsorbent resin column, ODS-A and Sephadex LH-20 chromatography, followed by preparative HPLC. This peptide shows inhibitory activity against HIV-1 protease. The structure was elucidated by spectroscopic approaches, including ESI-MS and various NMR methods. Absolute configuration of the amino acid residues in 4862F was defined using Marfey's method, and the structure was identified as $N, N, N$-(trimethylated)-Tyr-L-Leu-L-Val-L-Leu(dehydrated)-His. The peptide $4862 \mathrm{~F}$ displays inhibitory activity against HIV-1 protease, with $\mathrm{IC}_{50}$ values of $15.26 \mathrm{nM}$, using a fluorescence-based assay.
\end{abstract}

Keywords: Streptomyces albosporus; structure elucidation; HIV-1 protease inhibitor

\section{Introduction}

The protease of human immunodeficiency virus type 1 is an essential enzyme in the viral life cycle where it cleaves the viral Gag-Pol polyprotein precursor into Gag proteins and two enzymes, integrase and protease [1]. Inhibition of this enzyme has been used successfully for the treatment of HIV-1- 
infected patients. Some HIV protease inhibitors, such as saquinavir, indinavir, and ritonavir, have been widely used clinically for the treatment of acquired Immunodeficiency syndrome (AIDS) patients. However, long-term use of these protease inhibitors leads to significant adverse effects and drug resistance. Therefore, it is imperative to find novel HIV-1 protease inhibitors.

Microbial fermentation products are important resources for the discovery of leading compounds with new structure and bioactivity. We are interested in the isolation of new inhibitors of HIV-1 protease, and the microbial products from an actinomycete strain Streptomyces albosporus I03A04862 exhibited promising activity. We found that $1 \mathrm{mg} \cdot \mathrm{mL}^{-1}$ of fermentation product (dried powder) from I03A-04862 could inhibit $50.2 \%$ of the activity of HIV-1 protease. This strain was classified as a member of the Streptomyces genus on the basis of $16 \mathrm{~S}$ rRNA sequence analysis. A new pentapeptide has been isolated from the fermentation broth of this strain using a combination of Diaion HP-20 macroporous adsorbent resin column, ODS-A and Sephadex LH-20 chromatgraphy and preparative HPLC. Here we report the isolation and structure elucidation of this new compound. We also provide evidence for the demonstration of its inhibitory activity against HIV-1 protease in vitro.

\section{Results and Discussion}

The compound 4862F (Figure 1) was isolated as a white amorphous powder and its molecular formula was established as $\mathrm{C}_{35} \mathrm{H}_{53} \mathrm{~N}_{7} \mathrm{O}_{7}$ according to the HR-ESI $(+)$ mass spectra, where the $[\mathrm{M}+\mathrm{H}]^{+}$ ion was observed at $m / z 684.40954$ and $[\mathrm{M}+2 \mathrm{H}]^{2+}$ was observed at $m / z 342.70860$ (calcd for $\mathrm{C}_{35} \mathrm{H}_{54} \mathrm{~N}_{7} \mathrm{O}_{7}$ 684.40847), $[\alpha]^{20}{ }_{\mathrm{D}}+18^{\circ}(\mathrm{MeOH}, \mathrm{c} 0.1)$.

Figure 1. The structure of $4862 \mathrm{~F}$.

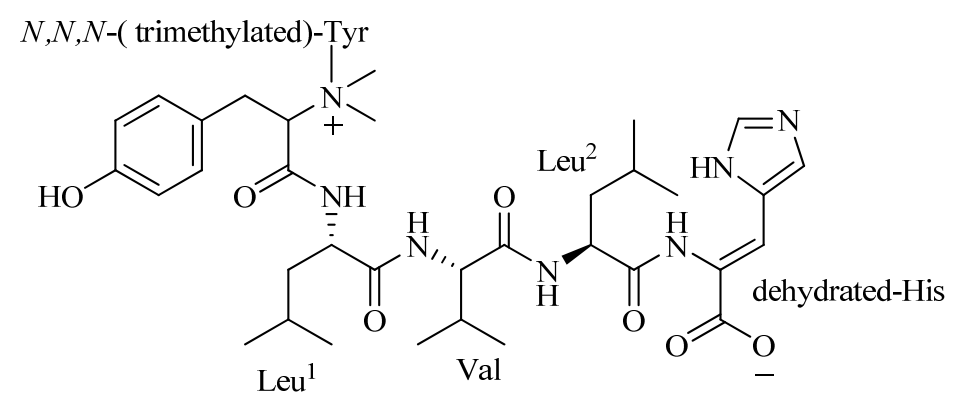

The ${ }^{13} \mathrm{C}$-NMR and DEPT spectra of 4862F (Table 1) showed a total of 35 carbon signals, consisting of nine methyl groups including three $N$-methyls, three methylenes, fourteen methines, and nine quaternary carbons including five carboxyls. Interpretation of ${ }^{1} \mathrm{H},{ }^{13} \mathrm{C},{ }^{1} \mathrm{H}-{ }^{1} \mathrm{H}$ COSY, HSQC, and HMBC data of $4862 \mathrm{~F}$ established the amino acid residues as leucine (Leu, $2 \times$ ), valine (Val), and tyrosine (Tyr). In the HMBC spectrum, the $N-\mathrm{CH}_{3}$ signal $\left(\delta_{\mathrm{C}} 53.255\right)$ showed a cross-peak to the $\alpha-\mathrm{H}$ signal of $\operatorname{Tyr}\left(\delta_{\mathrm{H}} 4.046\right)$. The ${ }^{1} \mathrm{H}-\mathrm{NMR}$ spectra in $\mathrm{D}_{2} \mathrm{O}$ and $2 \% d$-TFA showed nine protons $\left(\delta_{\mathrm{H}} 3.128\right)$ covered up by the solvent peak when $\mathrm{CD}_{3} \mathrm{OD}$ was used as the solvent, which were correlated to the $N-\mathrm{CH}_{3}$ signal $\left(\delta_{\mathrm{C}} 53.255\right)$ in the HSQC. This evidence indicates that the $\mathrm{N}$ of the Tyr residue was substituted by three methyls. The residue peaks suggests the presence of a histidine (His), which was dehydrated.

The amino acid sequence of 4862F was analyzed using the HMBC correlations (Table 1, Figure 2) from relevant $\alpha-\mathrm{H}$ to neighboring carboxylic carbons. The $\mathrm{Leu}^{1} \alpha-\mathrm{H}\left(\delta_{\mathrm{H}} 4.363\right)$ signal showed an 
HMBC correlation to the amide carbon signal of trimethylated-Tyr $\left(\delta_{\mathrm{C}} 166.550\right)$, indicating that it is acylated by trimethylated-Tyr. In the HMBC spectrum, the $\alpha-\mathrm{H}$ signal of Val $\left(\delta_{\mathrm{H}} 4.005\right)$ showed a cross-peak to the amide carbon signal of $\operatorname{Leu}^{1}\left(\delta_{\mathrm{C}} 172.756\right)$, the $\alpha-\mathrm{H}$ signal of $\mathrm{Leu}^{2}\left(\delta_{\mathrm{H}} 4.335\right)$ showed a cross-peak to the amide carbon signal of Val $\left(\delta_{\mathrm{C}} 174.520\right)$ and the $\beta$-H signal of the dehydrated-His $\left(\delta_{\mathrm{H}} 4.335\right)$ showed a cross-peak to the amide carbon signal of $\mathrm{Leu}^{2}\left(\delta_{\mathrm{C}} 174.101\right)$. These correlations enabled assignment of the linear sequence for $4862 \mathrm{~F}$.

Table 1. NMR Spectroscopic Data of $4862 \mathrm{~F}$ in $\mathrm{CD}_{3} \mathrm{OD}$.

\begin{tabular}{|c|c|c|c|c|}
\hline Unit & Pos. & $\delta C^{a}$, mult. & $\delta H^{b}(J$ in $H z)$ & HMBC $(\mathrm{H} \rightarrow \mathrm{C})$ \\
\hline \multirow{9}{*}{$N, N, N$-trimethyl-Tyr } & $\mathrm{CO}$ & 166.550, qC & & \\
\hline & $\alpha$ & 77.147, $\mathrm{CH}$ & $4.046, \mathrm{dd}(11,4)$ & $\mathrm{CO}, \beta, 1, \mathrm{~N}-\mathrm{Me}$ \\
\hline & $\beta$ & $32.979, \mathrm{CH}_{2}$ & $3.139, \mathrm{dd}(13,11)$ & $\mathrm{CO}, 1,2 / 6, \alpha$ \\
\hline & & & $3.257, \mathrm{~m}^{c}$ & \\
\hline & 1 & 125.257, qC & & \\
\hline & $2 / 6$ & 116.909, CH & $6.967, \mathrm{~d}(8.5)$ & $\beta, 3 / 5,4$ \\
\hline & $3 / 5$ & 131.441, CH & $6.642, \mathrm{~d}(8.5)$ & 1,4 \\
\hline & 4 & $158.085, \mathrm{qC}$ & & \\
\hline & $N$-Me & $53.255,3 * \mathrm{CH}_{3}$ & $3.234, \mathrm{~s}$ & $\alpha$ \\
\hline \multirow{6}{*}{$\mathrm{Leu}^{1}$} & $\mathrm{CO}$ & $172.756, \mathrm{qC}$ & & \\
\hline & $\alpha$ & $53.357, \mathrm{CH}$ & $4.363, \mathrm{~m}^{c}$ & $\mathrm{CO}, \mathrm{CO}(\mathrm{Tyr}), \beta, \gamma$ \\
\hline & $\beta$ & $42.091, \mathrm{CH}_{2}$ & $1.430, \mathrm{~m}^{c}$ & $\mathrm{CO}, \alpha, \gamma, \delta, \delta^{\prime}$ \\
\hline & $\gamma$ & $25.918, \mathrm{CH}$ & $1.388, \mathrm{~m}^{c}$ & $\mathrm{CO}, \alpha, \beta, \delta, \delta^{\prime}$ \\
\hline & $\delta$ & $23.177, \mathrm{CH}_{3}$ & $0.828, \mathrm{~d}(6.5)$ & $\alpha, \beta, \gamma, \delta^{\prime}$ \\
\hline & $\delta{ }^{\prime}$ & $22.319, \mathrm{CH}_{3}$ & $0.806, \mathrm{~d}(6)$ & $\alpha, \beta, \gamma, \delta$ \\
\hline \multirow{5}{*}{ Val } & $\mathrm{CO}$ & 174.520, qC & & \\
\hline & $\alpha$ & $60.443, \mathrm{CH}$ & $4.005, \mathrm{~d}(8)$ & $\mathrm{CO}, \mathrm{CO}\left(\mathrm{Leu}^{1}\right), \beta, \gamma, \gamma^{\prime}$ \\
\hline & $\beta$ & $31.630, \mathrm{CH}$ & $1.991, \mathrm{~m}^{c}$ & $\mathrm{CO}, \alpha, \gamma, \gamma^{\prime}$ \\
\hline & $\gamma$ & $19.623, \mathrm{CH}_{3}$ & $0.877, \mathrm{~m}^{c}$ & $\alpha, \beta, \gamma$ \\
\hline & $\gamma^{\prime}$ & $19.351, \mathrm{CH}_{3}$ & $0.916, \mathrm{~m}^{c}$ & $\alpha, \beta, \gamma^{\prime}$ \\
\hline \multirow{6}{*}{$\mathrm{Leu}^{2}$} & $\mathrm{CO}$ & 174.101, qC & & \\
\hline & $\alpha$ & $54.110, \mathrm{CH}$ & $4.335, \mathrm{~m}^{c}$ & $\mathrm{CO}, \mathrm{CO}(\mathrm{Val}), \beta, \gamma$ \\
\hline & $\beta$ & $40.700, \mathrm{CH}_{2}$ & 1.657, $\operatorname{dd}(7.5,7.5)$ & $\mathrm{CO}, \alpha, \gamma, \delta, \delta^{\prime}$ \\
\hline & $\gamma$ & $25.681, \mathrm{CH}$ & $1.760, \mathrm{~m}^{c}$ & $\alpha, \beta, \delta, \delta^{\prime}$ \\
\hline & $\delta$ & $23.405, \mathrm{CH}_{3}$ & $0.936, \mathrm{~d}(7)$ & $\beta, \gamma, \delta$ \\
\hline & $\delta^{\prime}$ & 21.887, $\mathrm{CH}_{3}$ & $0.884, \mathrm{~d}(6.5)$ & $\beta, \gamma, \delta^{\prime}$ \\
\hline \multirow{6}{*}{$(-2 H)$-His } & $\mathrm{CO}$ & 166.164, qC & & \\
\hline & $\alpha$ & 128.992, qC & & \\
\hline & $\beta$ & $119.794, \mathrm{CH}$ & $7.409, \mathrm{~s}$ & $\mathrm{CO}, \mathrm{CO}\left(\mathrm{Leu}^{2}\right), 1,5, \alpha$ \\
\hline & 1 & 128.745, qC & & \\
\hline & 3 & 136.069, CH & $8.902, \mathrm{~s}$ & 5,1 \\
\hline & 5 & $122.783, \mathrm{CH}$ & $7.882, \mathrm{~s}$ & $\beta, 1,3$ \\
\hline
\end{tabular}

${ }^{a}$ Recorded at $125 \mathrm{MHz} .{ }^{b}$ Recorded at $500 \mathrm{MHz} .{ }^{c}$ Multiplicity due to overlapping. 
Figure 2. Selected 2D NMR correlations for 4862F.

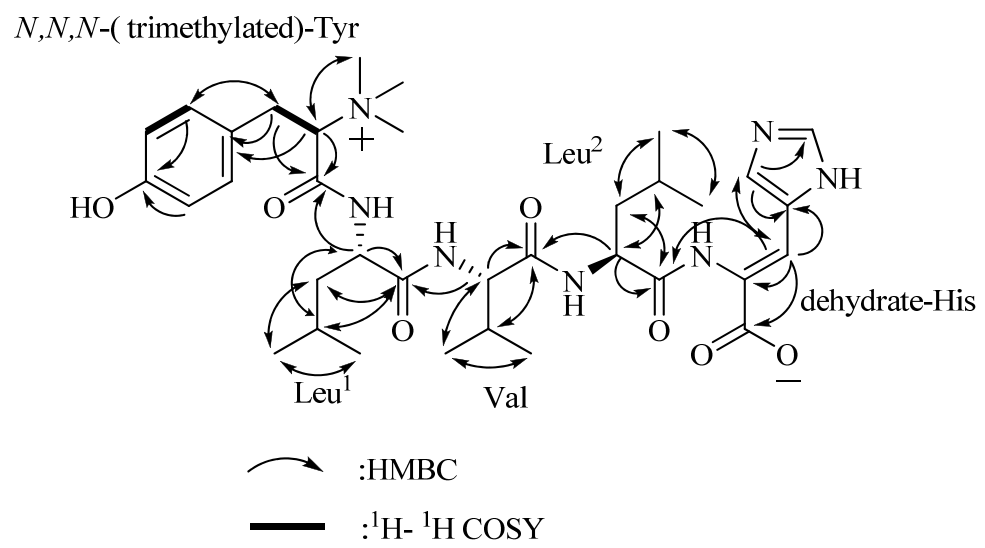

The whole structure of $4862 \mathrm{~F}$ was further confirmed by analysis of ESI-MS/MS spectra (Figure 3). The fragment ion $\mathrm{m} / \mathrm{z} 625.16$ also confirmed that the $N$ of Tyr is trimethylated. The fragment ion $\mathrm{m} / \mathrm{z}$ 531.24 demonstrated that the amino acid residue of the C-terminal is a dehydrated-His.

Figure 3. ESI-MS/MS data of 4862F.

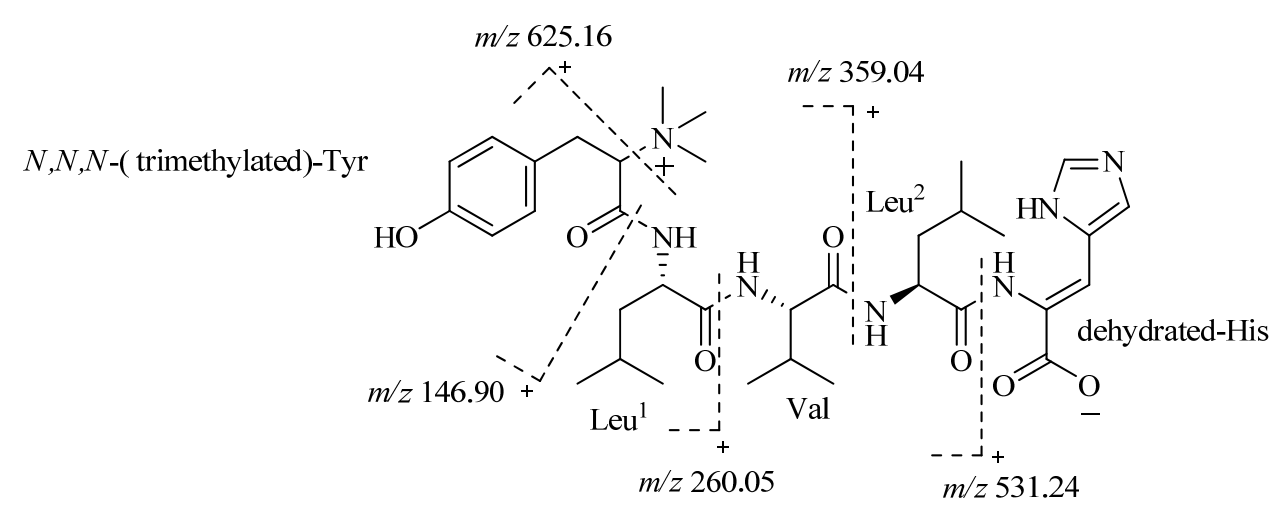

Marfey's method [2,3] was employed to assign the absolute configurations of the amino acid residues resulting from acid hydrolysis of 4862F. The 1-fluoro-2,4-dinitrophenyl-5-L-alanine amide (FDAA) derivatives of the acid hydrolysate of $4862 \mathrm{~F}$ and the authentic D- and L-amino acids were subjected to HPLC analysis. The absolute configurations of all amino acid residues in 4862F except for trimethylated-Tyr and dehydrated-His were established by comparing their HPLC retention times with those of the corresponding authentic D- and L-standards. The results indicate that all the amino acid residues have L-configuration (Table 2).

Table 2. HPLC Analysis of FDAA Derivatized Acid Hydrolysates of Compound 4862F.

\begin{tabular}{ccc}
\hline Amino acid & $\boldsymbol{t} \mathbf{R}(\mathbf{m i n})$ & $\boldsymbol{t} \mathbf{R}(\mathbf{m i n})$ of FDAA derivatized acid hydrolysates of compound $\mathbf{4 8 6 2} \mathbf{F}$ \\
\hline L-Leu & 32.335 & 32.491 \\
D-Leu & 38.252 & \\
L-Val & 26.959 & 26.527 \\
D-Val & 32.950 & \\
\hline
\end{tabular}


However, the determination of the absolute configuration of the trimethylated-Tyr using Marfey's method and the $Z, E$ - configuration of the trimethylated-Tyr residue was unsuccessful, because commercial standard materials are not available for these two residues.

To our knowledge, the structure of $4862 \mathrm{~F}$ has not been previously reported in the literature. The trimethylated-Tyr residue has only been reported in publications a few times, and the dehydrated-His residue has not yet been reported.

Compound $4862 \mathrm{~F}$ was further tested for the inhibition of HIV-1 protease, and the $\mathrm{IC}_{50}$ value is $15.26 \mathrm{nM}$ (Table 3) based on an established model used for high-throughput fluorescence detection for HIV-1 protease substrate [4]. As the positive control, indinavir showed $\mathrm{IC}_{50}$ values of $4.6 \mathrm{nM}$. In contrast, $4862 \mathrm{~F}$ did not show any inhibitory activity against the HIV-1 reverse transcriptase at $200 \mu \mathrm{g} \cdot \mathrm{mL}^{-1}$, indicating the specificity of this compound.

Table 3. Raw data of inhibitory activity of $4862 \mathrm{~F}$ on HIV-1 protease.

\begin{tabular}{lllllllllll}
\hline $\operatorname{Lg}(4862 \mathrm{~F}, \mathrm{nM})$ & 3.17 & 2.87 & 2.57 & 2.27 & 1.95 & 1.65 & 1.35 & 1.05 & 0.75 & 0.45 \\
\hline Mean of inhibition (\%) & 94.70 & 93.55 & 87.25 & 82.00 & 73.70 & 58.95 & 46.10 & 49.50 & 38.35 & 32.60 \\
\hline
\end{tabular}

\section{Experimental}

\subsection{General Methods}

Column chromatography was performed with Diaion HP-20, ODS-A and Sephadex LH-20 (Mitsubishi Chemical Analytech Co., Ltd, Yokkaichi-shi, Mie, Japan). Semi-preparative HPLC was performed using an ODS column (Zorbax SB-C18 column; $5 \mu \mathrm{m} ; 9.4 \times 250 \mathrm{~mm} ; 2 \mathrm{~mL} \cdot \mathrm{min}^{-1} ; 280 \mathrm{~nm}$ ). HPLC analysis was performed using an ODS column (Shimadzu C18 column; $5 \mu \mathrm{m}, 4.6 \times 150 \mathrm{~mm}$; $1.0 \mathrm{~mL} \cdot \mathrm{min}^{-1} ; 280 \mathrm{~nm}$ ) at $40{ }^{\circ} \mathrm{C}$. ESI-MS data were acquired using a LTQ ORBITRAP XL mass spectrometer (Thermo-Fisher, Waltham, MA, USA). ${ }^{1} \mathrm{H}-,{ }^{13} \mathrm{C}-\mathrm{NMR}$ and DEPT spectra and 2D-NMR were recorded on a Bruker AV500-Ш spectrometer (Bremen, Germany) equipped with a $5 \mathrm{~mm}$ PABBO probe head, using TMS as internal standard and chemical shifts were recorded as $\delta$ values. The spectra were measured in $\mathrm{CD}_{3} \mathrm{OD}$, and the chemical shifts were referenced to the residual solvent signal $\left(\delta_{\mathrm{H}} 4.839,3.251\right.$ and $\left.\delta_{\mathrm{C}} 48.997\right) .{ }^{1} \mathrm{H}$ spectra were also measured in $\mathrm{D}_{2} \mathrm{O}$ and $2 \% d-\mathrm{TFA}$, and chemical shifts were referenced to the residual solvent signal $\left(\delta_{\mathrm{H}} 4.800\right)$. Optical rotations were measured on a Perkin-Elmer model 343 polarimeter (Waltham, MA, USA).

\subsection{Strain}

Streptomyces sp. I03A-04862 was stored at the China Medicinal Microbiological Culture Collection Center (Institute of Medicinal Biotechnology, Chinese Academy of Medical Sciences and Peking Union Medical College, No. I03A-04862) at $-80{ }^{\circ} \mathrm{C}$.

\subsection{Fermentation}

Streptomyces sp. I03A-04862 was incubated in a rotary shaker $(220 \mathrm{rpm})$ at $28^{\circ} \mathrm{C}$ for $48 \mathrm{~h}$ in $500 \mathrm{~mL}$ Erlenmeyer flasks containing $100 \mathrm{~mL}$ medium consisting of glucose $0.5 \%$, yeast extract $0.5 \%$, peptone $0.5 \%$, beef extract $0.5 \%$, corn steep liquor $0.4 \%$, soybean meal $1 \%$, soluble starch $1.0 \%, \mathrm{CaCO}_{3} 0.4 \%$, 
and $\mathrm{CoCl}_{2} \cdot 6 \mathrm{H}_{2} \mathrm{O} 0.002 \%$ in deionized water ( $\mathrm{pH} 7.2$ before sterilization) and then scaled up to $5,000 \mathrm{~mL}$ flasks containing $1,000 \mathrm{~mL}$ of the medium. The fermentations were carried out at $28{ }^{\circ} \mathrm{C}$ for $96 \mathrm{~h}$ with aeration and agitation.

\subsection{Extraction and Isolution}

The whole fermentation broth (30 L) was filtered to separate into supernatant and mycelia fractions. The mycelia were extracted three times with acetone $(3 \mathrm{~L})$. The acetone solution was evaporated under reduced pressure to afford an aqueous solution. The aqueous solution and the supernatant were subjected to Diaion HP-20 macroporous adsorbent resin column chromatography (3 L). A successive elution of the column with $\mathrm{H}_{2} \mathrm{O}$ and $30 \%, 50 \%, 75 \%$ and $100 \%$ acetone in $\mathrm{H}_{2} \mathrm{O}$ yielded five corresponding fractions (HP-0\% HP-100\%) after removal of solvents. Fractions HP-30\% and HP$50 \%(1 \mathrm{~g})$, with $68.3 \%$ inhibitory activity on HIV-1 protease at $1 \mathrm{mg} \cdot \mathrm{mL}^{-1}$ were purified by column chromatography using ODS-A (200 mL), and eluted successively with 40\%, 50\%, 60\%, 80\% and $100 \%$ aqueous methanol solution to yield five corresponding subfractions (ODS-40\% ODS-100\%) after removal of solvents. The fractions ODS-50\% and ODS-60\% (93.4 mg, yield 9.3\%) with 78.3\% inhibitory activity on HIV-1 protease at $1 \mathrm{mg} \cdot \mathrm{mL}^{-1}$ were separated by column chromatography using Sephadex LH-20 eluted with water (30.2 mg, dried power, yield $32.3 \%$, with $90.3 \%$ inhibitory activity on HIV-1 protease at $1 \mathrm{mg} \cdot \mathrm{mL}^{-1}$ ) and then subjected to reversed phase semi-preparative HPLC twice using a mobile phase of $45 \%$ methanol aqueous solution containing $0.1 \%$ trifluoroacetic acid (TFA) to yield $4862 \mathrm{~F}\left(t_{\mathrm{R}} 19.6 \mathrm{~min}, 8.5 \mathrm{mg}\right.$, yield $28.2 \%$, with $99.3 \%$ inhibitory activity on $\mathrm{HIV}-1$ protease at $1 \mathrm{mg} \cdot \mathrm{mL}^{-1}$ ).

\subsection{Absolute Configuration}

Solutions of $4862 \mathrm{~F}(0.5 \mathrm{mg})$ in $6 \mathrm{~N} \mathrm{HCl}(1.0 \mathrm{~mL})$ were heated at $110{ }^{\circ} \mathrm{C}$ for $24 \mathrm{~h}$. Upon removal of excess $\mathrm{HCl}$ under vacuum, the hydrolysates were placed in a $1 \mathrm{~mL}$ reaction vial and treated with a $1 \%$ solution of 1-fluoro-2,4-dinitrophenyl-5-L-alanine amide (FDAA, $150 \mu \mathrm{L}$ ) in acetone, followed by $1 \mathrm{~N}$ $\mathrm{NaHCO}_{3}(40 \mu \mathrm{L})$. The reaction mixtures were incubated at $45{ }^{\circ} \mathrm{C}$ for $1.5 \mathrm{~h}$, cooled to room temperature, and then acidified with $2 \mathrm{~N} \mathrm{HCl}(20 \mu \mathrm{L})$. Similarly, the standard L- and D-amino acids were derivatized separately. The derivatives of the hydrolysates and the standard amino acids were subjected to HPLC analysis using a mobile phase of $45 \%$ methanol aqueous solution containing $0.1 \%$ trifluoroacetic acid (TFA). The retention times for FDAA derivatives of the hydrolysates and the standard amino acids are summarized in Table 2.

\subsection{Analysis of the Inhibition of HIV-1 Protease Activity by Compound $4862 \mathrm{~F}$}

The assay method for HIV protease activity measurement is based on intramolecular fluorescence resonance energy transfer (FRET) developed by Edmund [5] and Dong [4]. The assay uses quenched fluorogenic substrates containing a peptide sequence derived from a natural processing site for HIV-1 protease. The quenched fluorogenic substrate (obtained from Sigma, St. Louis, MO, USA) was Arg-Glu (EDANS)-Ser-Gln-Asn-Tyr-Pro-Ile-Val-Gly-Lys-(DABCYL)-Arg, where the fluorescent donor is EDANS and the quenching acceptor is DABCYL. Recombinant HIV-1 protease was expressed in E. coli JM109 and purified to homogeneity [6]. Briefly, E. coli JM 109 (Novagen, 
Darmstadt, Germany) were transfected by a p100w plasmid coding for the corresponding enzyme. The insoluble recombinant protein, accumulated in the form of inclusion bodies, was isolated and solubilized in $8 \mathrm{M}$ urea, $10 \mathrm{mM}$ DL-dithiothreitol (DTT), and $20 \mathrm{mM}$ Tris-(hydroxymethyl)aminomethane (Tris, $\mathrm{pH}$ 8.0). The protease was purified by cation exchange chromatography using DEAE-sephacel and CM-cellulose (Sigma). Purified enzymes were stored at $-85^{\circ} \mathrm{C}$.

Incubation of recombinant HIV-1 protease with the fluorogenic substrate at $37{ }^{\circ} \mathrm{C}$ resulted in specific cleavage of a tyrosine-proline bond, causing an increase in fluorescence due to elimination of intramolecular quenching. In the presence of an inhibitor such as indinavir, the fluorescence signal was expected to decrease as the concentration of inhibitor increased. Thus, inhibition of HIV-1 protease by $4862 \mathrm{~F}$ in the presence of the fluorogenic substrate was observed as a decrease in fluorescence intensity. The data were obtained with a Polarstar spectrofluorometer (excitation at $340 \mathrm{~nm}$, emission at $490 \mathrm{~nm}$ ). All values were standardized with blanks. For all of the experiments, the protease was added last to keep the incubation time with inhibitor consistent.

\section{Conclusions}

A new inhibitor of HIV-1 protease, 4862F, has been isolated from the culture broth of Streptomyces albosporus I03A-04862, which was elucidated as $N, N, N$-(trimethylated)-Tyr-L-Leu-L-Val-L-Leu(dehydrated)-His. This compound displayed inhibitory activity against HIV-1 protease, with a $\mathrm{IC}_{50}$ value of $15.26 \mathrm{nM}$ using a fluorescence-based assay.

\section{Acknowledgments}

This study was supported by the Key New Drug Creation and Manufacturing Program (Grant Nos. 2012ZX09301002-001/003, 2010ZX2010ZX09401-403) funded by The Ministry of Science and Technology of the People's Republic of China.

\section{References}

1. Sven, A.D.; Andrew, C.; John, M.L.; Leah, M.L.; Francesc, G.; Juan, G.; Antonio, R.; Rafael, R.; Emilio, B.; Vicente, P.; et al. A short-term study of the safety, pharmacokinetics, and efficacy of ritonavir, an inhibitor of HIV-1 protease. N. Engl. J. Med. 1995, 333, 1528-1534.

2. Zou, X.W.; Niu, S.B.; Ren, J.W.; Li, E.W.; Liu, X.Z.; Che, Y.S. Verrucamides A-D, antibacterial cyclopeptides from Myrothecium verrucaria. J. Nat. Prod. 2011, 74, 1111-1116.

3. Marfey, P. Determination of D-amino acids. ii. Use of a bifunctional reagent, 1,5-difluoro-2,4dinitrobenzene. Carlsberg Res. Commun. 1984, 49, 591-596.

4. Dong, B.; Zhang, T.; Tao, P.Z. Adopting fluorescent substrate to establish the high throughput screening model for HIV-1 protease inhibitors. Chin. J. AIDS STD 2006, 12, 402-405.

5. Matayoshi, E.D.; Wang, G.T.; Krafft, G.A.; Erickson, J. Novel Fluorogenic Substrates for Assaying Retroviral Proteases by Resonance Energy Transfer. Science 1990, 247, 954-958. 
6. Wan, M.; Lon, B.N. Expression and purification of active form of HIV-1 protease from E. coli. Biochem. Mol. Boil. Int. 1995, 35, 899-912.

Sample Availability: Samples of the compound was stored at the National Center for Microbiol Drug Screening (Institute of Medicinal Biotechnology, Chinese Academy of Medical Sciences and Peking Union Medical College, No. $4862 \mathrm{~F}$ ) at $-20{ }^{\circ} \mathrm{C}$.

(C) 2013 by the authors; licensee MDPI, Basel, Switzerland. This article is an open access article distributed under the terms and conditions of the Creative Commons Attribution license (http://creativecommons.org/licenses/by/3.0/). 